\title{
INFLUÊNCIA DE DIFERENTES TRATAMENTOS TÉRMICOS NA MICROESTRUTURA E NAS PROPRIEDADES MECÂNICAS DE UM AÇO UTILIZADO EM EIXO DE AEROGERADOR*
}

\author{
Renardir Peixoto Maciel Júnior ${ }^{1}$ \\ Eveline Carvalho de Brito ${ }^{2}$ \\ Roberto Abreu Alencar 3 \\ Énio Pontes de Deus ${ }^{4}$
}

\section{Resumo}

Tratamentos térmicos são de grande importância para o desenvolvimento dos materiais, pois alteram as suas propriedades ou conferem-Ihes características determinadas. Neste trabalho, foram realizados dois tratamentos térmicos diferentes, recozimento pleno e normalização, em um aço utilizado como eixo de sustentação de aerogerador a fim de verificar as alterações nas microestruturas e propriedades mecânicas através de microscopia ótica, microscopia eletrônica de varredura e ensaio de microdureza Vickers. Além disso, foi realizada a identificação do material por meio de cálculo de composição de carbono utilizando o programa Image J com imagens obtidas por microscopia ótica. Logo, determinou-se que o aço tinha um teor de $0,55 \%$ de carbono. Após o estudo comparativo de dureza, verificou-se uma maior dureza da amostra normalizada e uma menor para a amostra recozida em comparação com a amostra recebida (sem tratamento). Logo, alcançaram-se os objetivos esperados ao fim do trabalho, pois todas as etapas foram realizadas com êxito obtendo,dessa forma, uma análise de resultados precisa.

Palavras-chave: Recozimento Pleno; Normalização; Microestrutura; Aço.

\section{EFFECT OF DIFFERENT THERMAL TREATMENTS IN THE MICROSTRUCTURE AND MECHANICAL PROPERTIES OF A STEEL USED IN AEROGERATOR AXIS}

\section{Abstract}

Thermal treatments are of great importance for the development of materials because it changes their properties or give them specific characteristics. In this work, two different thermal treatments were performed, full annealing and normalization, in a steel used as a wind turbine support axis to verify changes in microstructures and mechanical properties through optical microscopy, scanning electron microscopy and Vickers microhardness test. In addition, the material was identified by calculating carbon composition using the Image $\mathrm{J}$ program with images obtained by optical microscopy. Therefore, it was determined that the steel had a content of $0.55 \%$ carbon. After the comparative hardness study, a higher hardness of the normalized sample was verified and a lower one for the annealed sample compared to the sample received (without treatment). Therefore, the expected objectives were achieved at the end of the work because all the steps were carried out successfully, thus obtaining an accurate results analysis.

Keywords: Full annealing; Normalization; Microstructure; Steel.

1 Engenharia Metalúrgica/graduando, bolsista de iniciação científica, Departamento de Engenharia Metalúrgica e Materiais, Universidade Federal do Ceará, Fortaleza, Ceará e Brasil.

2 Engenharia Metalúrgica/graduando, bolsista de iniciação científica, Departamento de Engenharia Metalúrgica e Materiais, Universidade Federal do Ceará, Fortaleza, Ceará e Brasil.

3 Engenharia Metalúrgica/graduando, bolsista de iniciação científica, Departamento de Engenharia Metalúrgica e Materiais, Universidade Federal do Ceará, Fortaleza, Ceará e Brasil.

4 Engenheiro Civil, Doutorado, Professor Adjunto /Orientador, Departamento de Engenharia Metalúrgica e Materiais, Universidade Federal do Ceará, Fortaleza, Ceará e Brasil. 


\section{INTRODUÇÃO}

Kwietniewski(1) descreve: "pode-se definir tratamento térmico como um ciclo de aquecimento e resfriamento que tem como objetivo produzir propriedades mecânicas específicas, através de alterações microestruturais" (KWIETNIEWSKI, et al, 2014:94). Neste trabalho foi realizado recozimento pleno e normalização nas peças recebidas para posterior análise da dureza.

O recozimento pleno é realizado para aços hipoeutóides, onde aquece-se até temperatura de 20 a 40K acima do ponto Ac3. Posteriormente, o aço é resfriado com pequena velocidade para que a austenita se decomponha com pequeno grau de super-resfriamento. O resfriamento pode acontecer dentro do forno até 500$600^{\circ} \mathrm{C}$ e, depois, no ar calmo. A estrutura do aço hipoeutetóide após este tratamento é constituída de ferrita livre e perlita havendo a eliminação de estruturas prejudiciais, como granulação grosseira e a ferrita de Windmonstaten (que diminui fortemente a resistência ao choque).

$\mathrm{Na}$ normalização, o aço é aquecido até a temperatura de 30-50ํK acima da linha GSE e resfriado ao ar, o que possibilita um super resfriamento da austenita um pouco maior. Obtém-se, portanto, uma constituição do eutetóide mais fina (perlita fina ou sorbita) e um tamanho do grão eutetóide menor e, além disso, a fase livre decresce parcialmente (ferrita ou cementita secundária), formando-se o quaseeutetóide. Espera-se, assim, que a resistência do aço deve ser maior após normalização do que após recozimento. A normalização é utilizada como operação intermediaria para eliminar os constituintes prejudiciais, e para melhoria geral da estrutura antes da têmpera.

Desta forma, em muitos casos ambos os tratamentos dão o mesmo resultado, sendo a normalização então, mais vantajosa, pois utiliza menos o equipamento do forno. Porém, nem sempre a normalização pode substituir o recozimento como operação de amolecimento do aço, pois como a tendência da austenita ao superresfriamento cresce com a elevação de sua composição em carbono e elementos de liga, há diferenças nas propriedades dependendo da composição do aço.

Portanto, o principal objetivo desse trabalho é verificar as alterações microestruturais e de dureza no aço

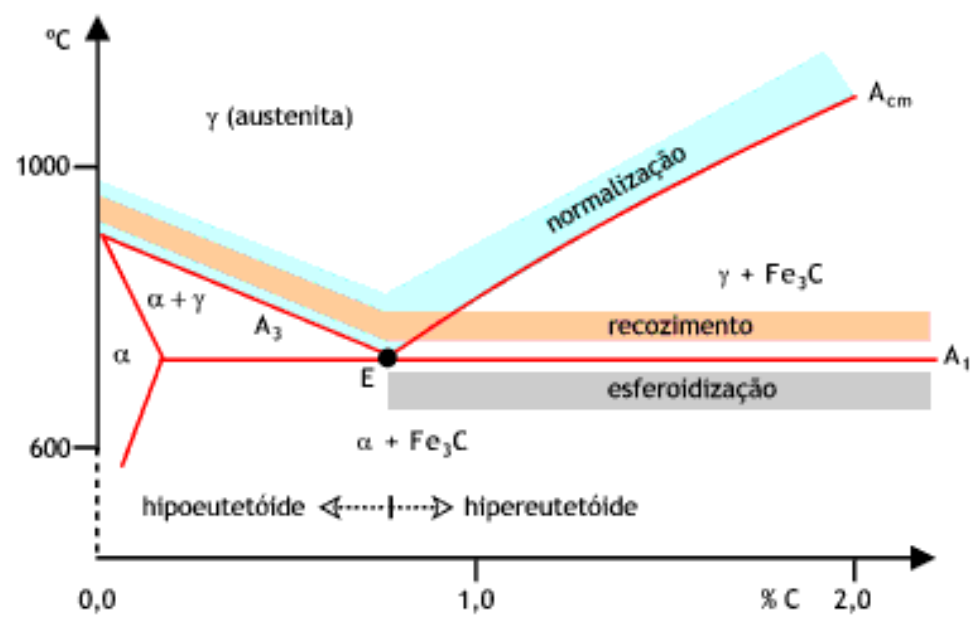

Fonte: http://www.mspc.eng.br/ciemat/aco140.shtml

Figura 1: Temperaturas para normalização, recozimento pleno e esferoidização. 


\section{MATERIAIS E MÉTODOS}

\subsection{Materiais}

\begin{tabular}{|l|l|}
\hline - Amostra de aço desconhecido; & - Panos de polimento; \\
- Máquina de Corte (Cut-off); & - Pasta de diamante ; \\
- Disco de Corte abrasivo; & - Microscópio Ótico; \\
- Máquina embutidora; & - Computador; \\
- Baquelite em pó & - Forno; \\
- Lixadeira; & - Microduromêtro Vickers; \\
- Politriz; & -Microscópio Eletrônico de Varredura; \\
- Lixas (granulometria: 80,240,400,600 & - Nital 2\% \\
e 1200); & \\
\hline
\end{tabular}

Quadro 1: Materiais utilizados

\subsection{Métodos}

\subsubsection{Metalografia}

A amostra foi recebida com o formato apresentado na Fig. 2. A fim de analisar as microestruturas das amostras no Microscópio Ótico (MO) e no Microscópio Eletrônico de Varredura, realizou-se o corte da amostra em pedaços menores, embutimento e uniformização da superfície com lixamento e polimento, seguido de ataque químico com nital $2 \%$ (98\% de ácido nítrico e $2 \%$ de álcool etílico) para revelação da microestrutura pelo $\mathrm{MO}$.

\subsubsection{Corte}

Essa etapa foi realizada na máquina cut-off do Laboratório de Metalografia da Universidade Federal do Ceará (UFC). Durante o processo a peça foi presa com firmeza na máquina e o disco foi pressionado com moderada tensão e com bastante lubrificação a fim de evitar a queima da amostra pelo superaquecimento através do contato prolongado do disco sob a amostra e mudanças na estrutura do material.

\subsubsection{Embutimento}

Para um melhor manuseio, todas as amostras foram embutidas a quente que apresenta maior qualidade e rapidez. Esta etapa também foi realizada no Laboratório de Metalografia da UFC..

\subsubsection{Lixamento}

Foram utilizadas lixas d'agua com diferentes granulometrias (80, 240, 400, 600 e 1200) nessa etapa. A cada troca de lixa, a amostra foi lavada com água, álcool e secada no calor para retirar qualquer sujeira da lixa anterior e posicionada na máquina com rotação de $90^{\circ}$ a fim de que a nova lixa tirasse por completo os riscos da lixa anterior. O lixamento das amostras foi realizado no Laboratório de Pesquisa em Corrosão da UFC.

\subsubsection{Polimento}

Esta etapa foi realizada no Laboratório de Caracterização de Materiais da UFC. Para essa etapa foi uilizada a pasta de diamante como abrasivo. 


\subsubsection{Ataque}

As amostras foram atacas com nital inicialmente por $2 \mathrm{~s}$, após observação no $\mathrm{MO}$, as amostras foram novamente imersas na solução por 1s. Essa etapa é realizada para revelar a microestrutura da amostra. É importante que as amostras sejam imersas por períodos curtos de tempo, principalmente quando a solução escolhida for o nital, uma vez que ele possui alta concentração e pode "queimar" a amostra, o que poderia acarretar na necessidade de um novo polimento e até a perda da amostra. Esta etapa foi realizadaa no Laboratório de Caracterização de Materias da UFC.

\subsubsection{Tratamento Térmico}

As amostras foram submetidas aos tratamentos térmicos de recozimento pleno e normalização onde foram aquecidas até $870^{\circ} \mathrm{C}$ e posteriormente resfriadas ao forno e ao ar, respectivamente. O tempo de permanência na temperatura de austenitização da amostra recozida foi de 13 min e para a amostra normalizada foi de 17 min. Aplicou-se 2 min para cada mm da menor dimensão da amostra.

\subsubsection{Microscopia Ótica}

Essa etapa foi realizada no Laboratório de Caracterização de Materiais da UFC. Utilizou-se o modo de campo claro para uma visualização geral da microestrutura já que visava identificar as fases presentes do material.

\subsubsection{Microscopia Eletrônica de Varredura}

Essa etapa foi realizada no Laboratório de Caracterização de Materiais da UFC. Utilizou-se o modo SE para medir a espessura das lamelas.

\subsubsection{Ensaio de Dureza}

Foi realizado microdureza Vickers em cinco pontos da peça como recebida e após os tratamentos térmicos, obtendo-se uma média da microdureza para cada amostra para efeitos comparativos.

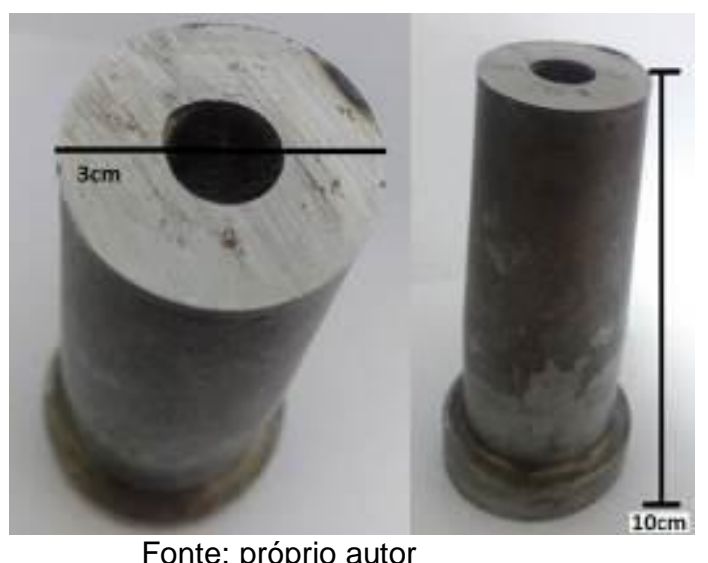

Fonte: próprio autor

Figura 2: Amostras como recebida.

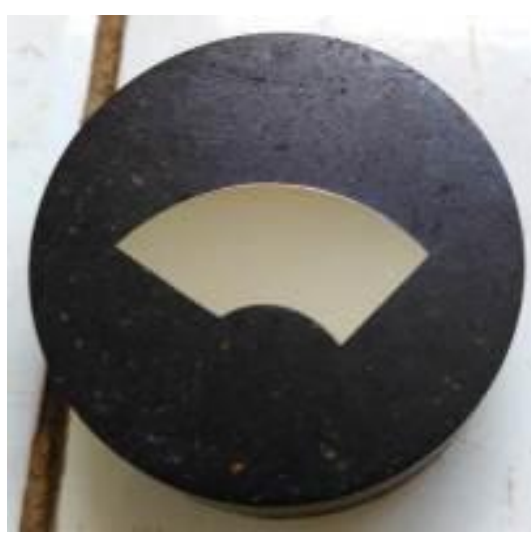

Fonte: próprio autor

Figura 3: Amostra após polimento.

\section{RESULTADOS E DISCUSSÃO}

Inicialmente, usando o programa IMAGEJ, obteu-se o teor de carbono do aço carbono com composição desconhecida ao quantificar a porcentagem de área 
ocupada por ferrita na microestrutura e realizar o cálculo da regra da alavanca. Segue abaixo os cálculos:

$$
\begin{gathered}
\frac{0,77-x}{0,77-0,021}=0,28194 \rightarrow x=0,558 \% \text { de } C \\
\text { Equação } 1
\end{gathered}
$$

\section{Equação 1}

Utilizou-se 3 amostras para obtenção de imagens de microestruturas e dados de microdureza Vickers, sendo uma amostra não tratada, uma após tratamento de normalização e outra após tratamento de recozimento pleno. Segue abaixo as imagens de microestrutura das amostras obtidas por microscopia ótica:

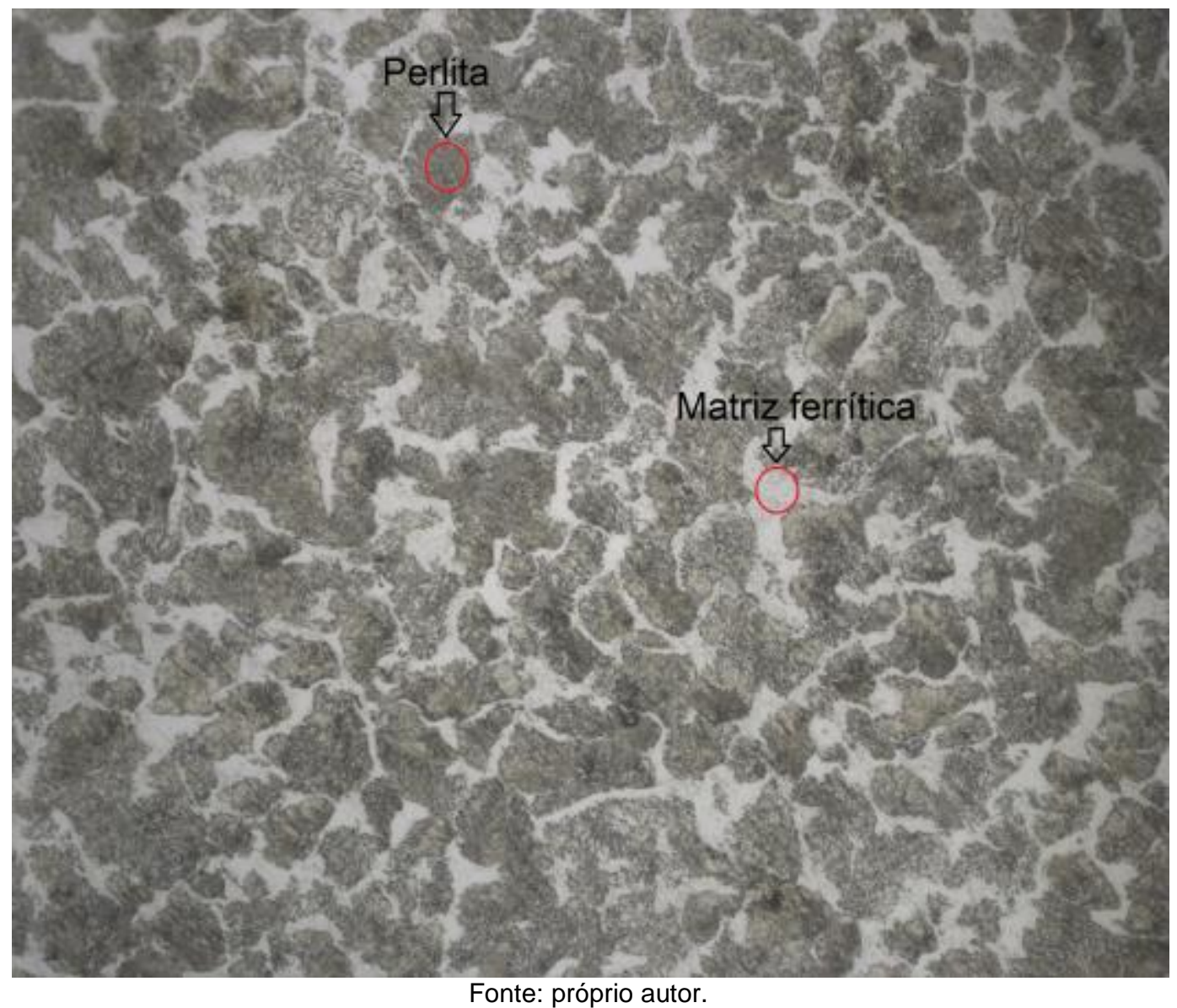

Figura 4: Microestrutura do aço SAE 1055 sem tratamento térmico com aumento de 500x. 


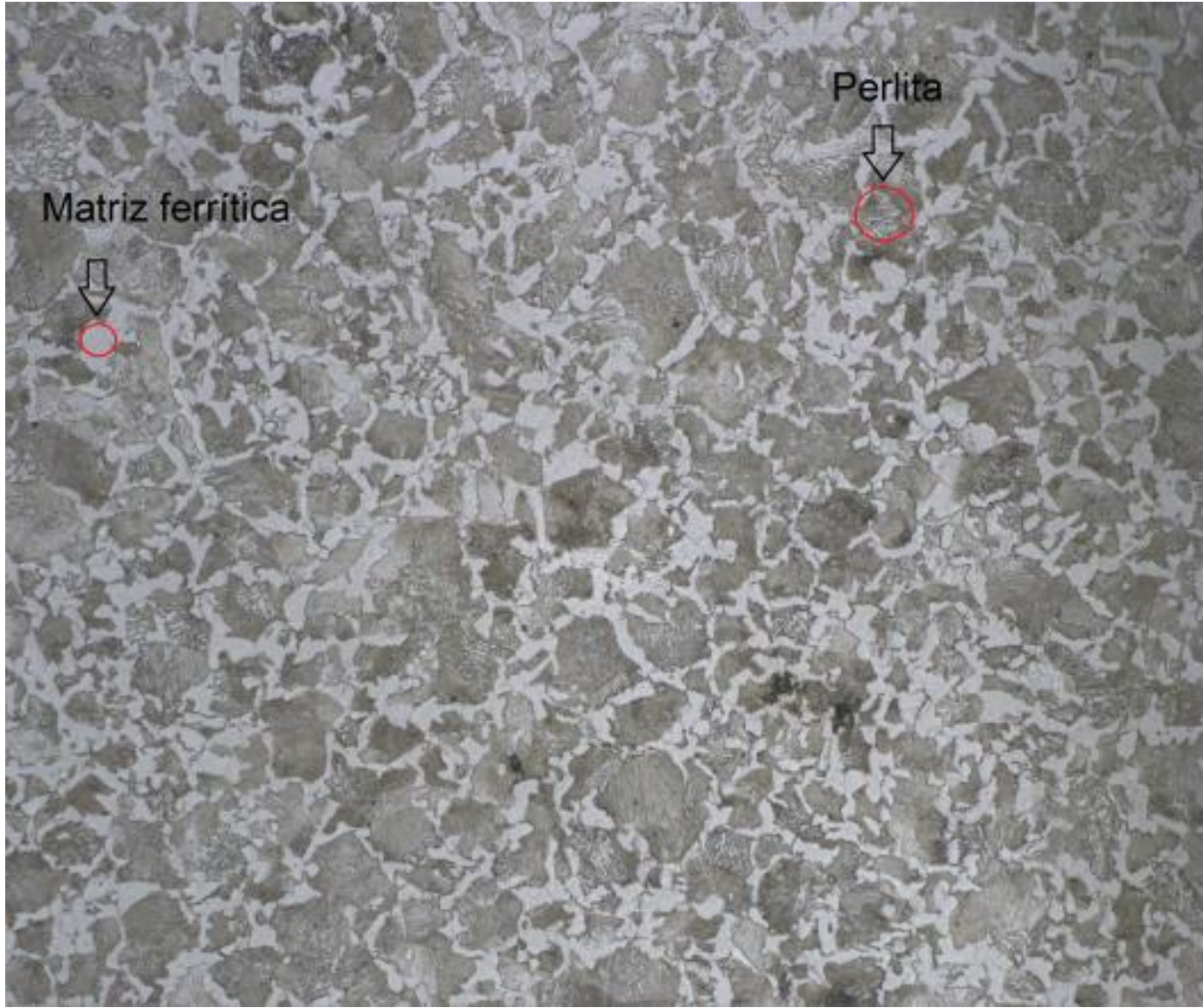

Fonte: próprio autor.

Figura 5: Microestrutura do aço SAE 1055 após normalização com aumento de 500x.

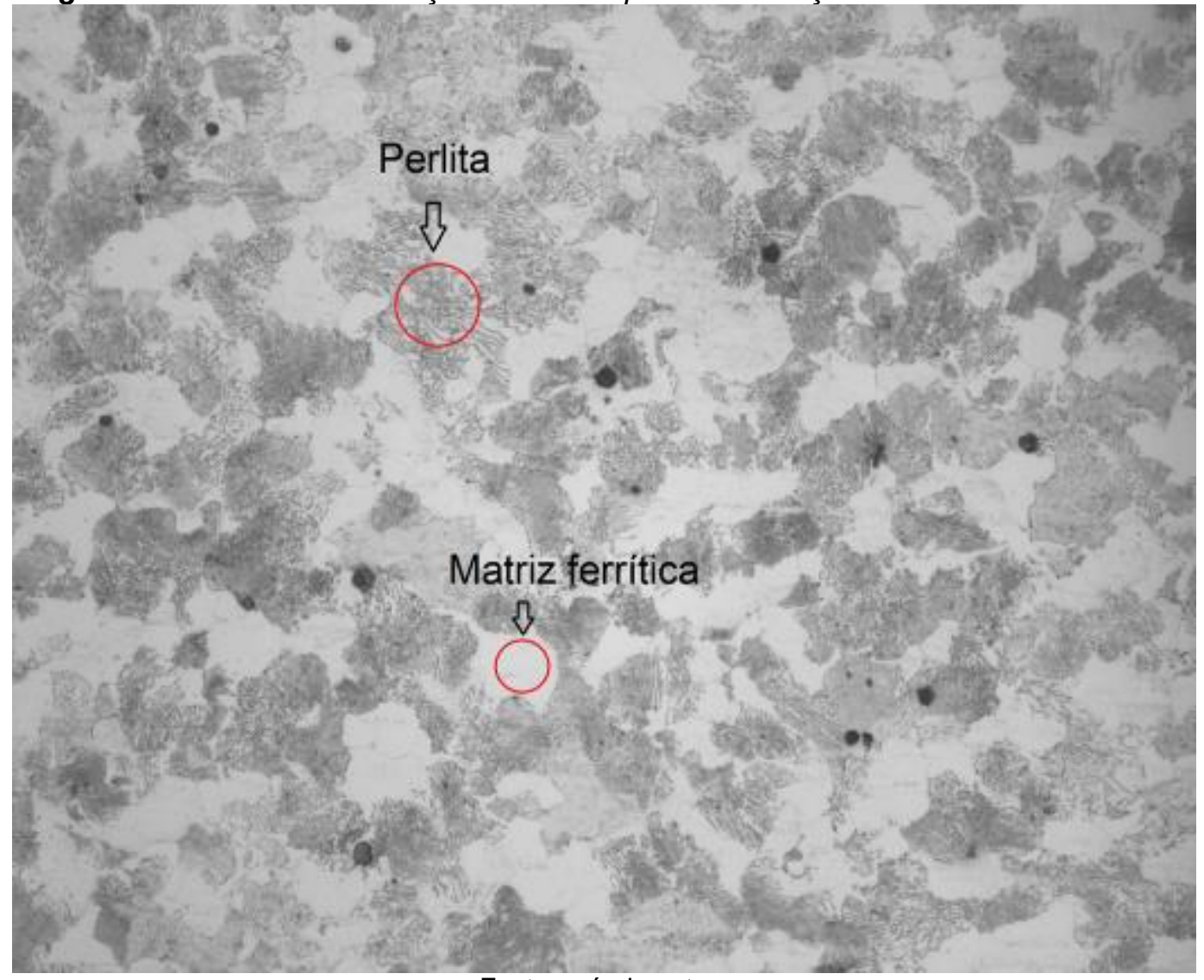

Fonte: próprio autor.

Figura 6: Microestrutura do aço SAE 1055 após recozimento pleno com aumento de 500x. 
A análise das imagens de microestrutura obtidas por microscopia ótica permite afirmar que a amostra recebida realmente se trata de um aço $\mathrm{Fe}-\mathrm{C}$ sem elementos de liga, pois é possível ver as colônias de perlita formada por lamelas alternadas de cementita e ferrita próeutetóide numa matriz ferrítica.

Segue abaixo as imagens de microestrutura das amostras obtidas por microscopia eletrônica de varredura para verificar a alteração na espessura das lamelas e no espaço interlamelar:

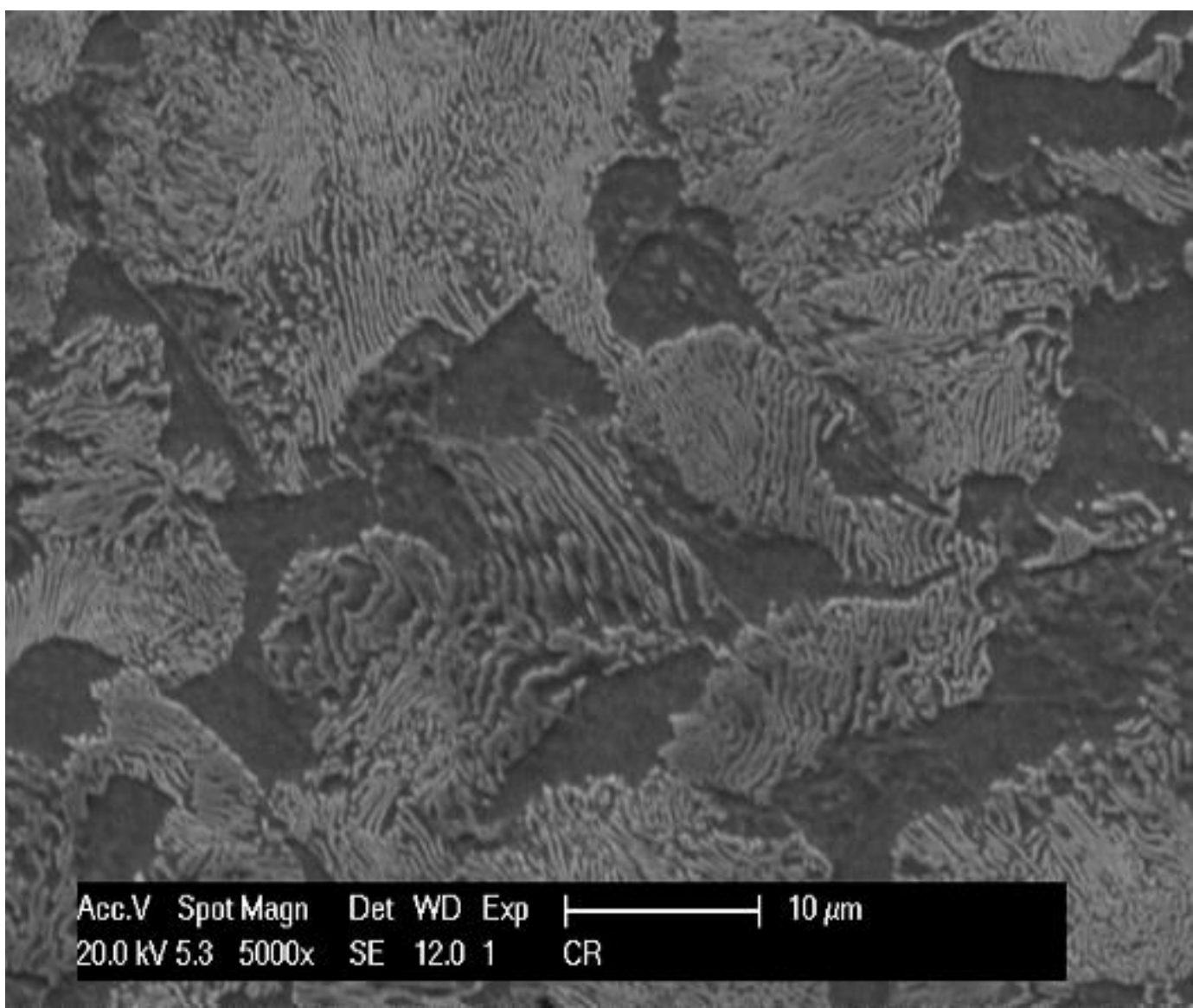

Fonte: próprio autor.

Figura 7: Microestrutura do aço SAE 1055 sem tratamento com aumento de 5000x. 


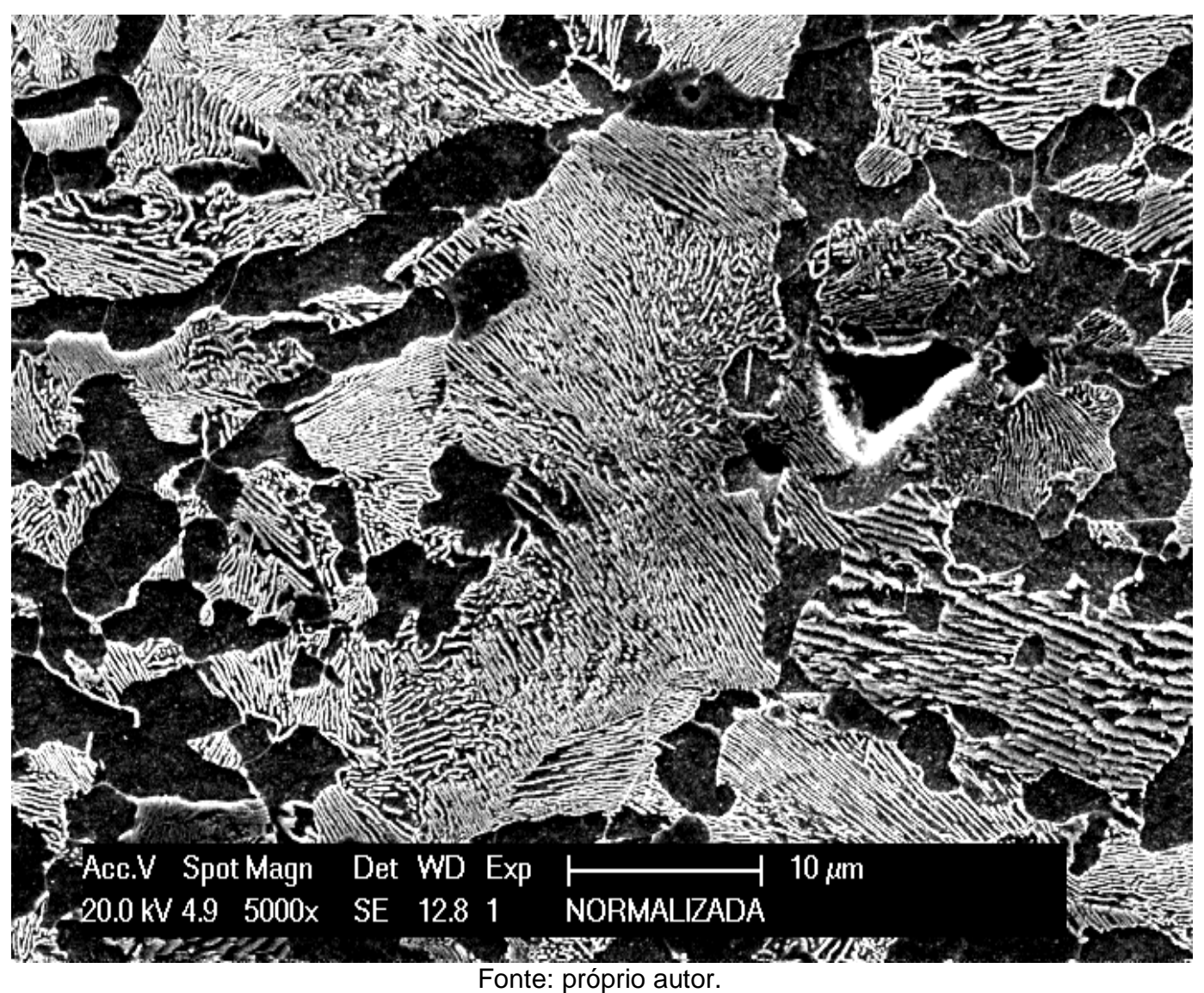

Figura 8: Microestrutura do aço SAE 1055 sem tratamento com aumento de 5000x.

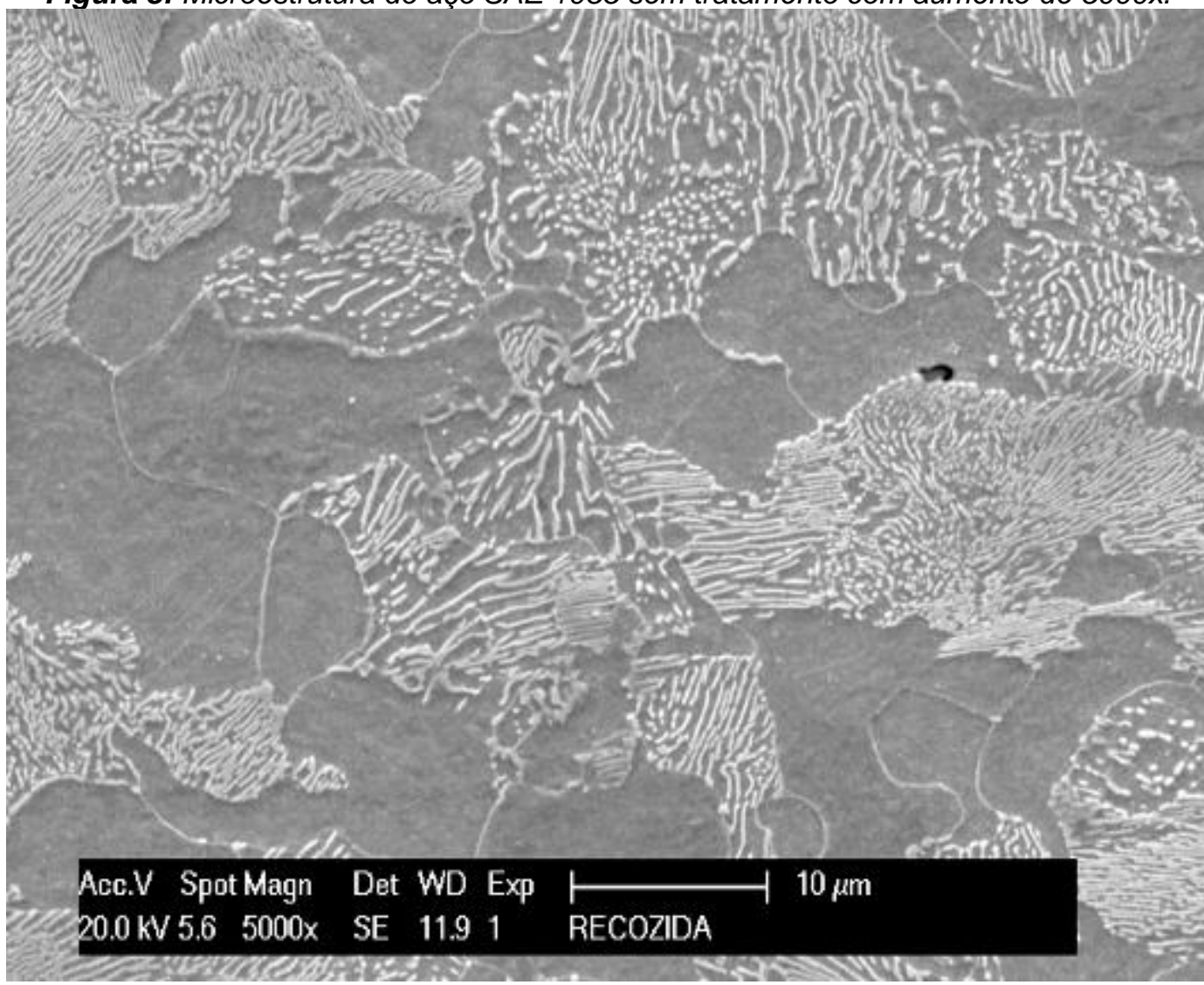

Fonte: próprio autor.

Figura 9: Microestrutura do aço SAE 1055 após recozimento pleno com aumento de 5000x. 
Com uso de uma ferramenta de medida do MEV, foram obtidas as medidas aproximadas das lamelas e realizou-se a média de 10 medidas. Segue abaixo a tabela com os resultados:

Tabela 1. Medidas de espessura das lamelas de cementita da perlita.

\begin{tabular}{|c|c|c|}
\hline Amostra como recebida & Amostra recozida & Amostra normalizada \\
\hline $399,43 \mathrm{~nm}$ & $696,57 \mathrm{~nm}$ & $302,42 \mathrm{~nm}$ \\
\hline
\end{tabular}

Fonte: próprio autor.

Da análise das microestruturas obtidas por MEV e da tabela 1, percebe-se que após o tratamento térmico de recozimento pleno, a espessura das lamelas aumentaram (perlita grosseira) junto com o aumento da quantidade de ferrita livre devido ao resfriamento lento que permite a ocorrência da difusão mais acentuada de carbono. De outro lado, após a normalização, essa espessura diminuiu (perlita fina ou sorbita), pois não há tempo para ocorrer a difusão devido ao resfriamento mais rápido.

Segue abaixo a tabela com os resultados do ensaio de microdureza Vickers com força de compressão de $980.7 \mathrm{mN}$ e HV 0.1 :

Tabela 2. Valores de microdureza das amostras.

\begin{tabular}{|c|c|c|c|}
\hline Medida 01 & $\begin{array}{c}\text { Amostra sem } \\
\text { tratamento }\end{array}$ & Amostra recozida & $\begin{array}{c}\text { Amostra } \\
\text { normalizada }\end{array}$ \\
\hline Medida 02 & $238 \mathrm{HV}$ & $209 \mathrm{HV}$ & $223 \mathrm{HV}$ \\
\hline Medida 03 & $217 \mathrm{HV}$ & $203 \mathrm{HV}$ & $217 \mathrm{HV}$ \\
\hline Medida 04 & $206 \mathrm{HV}$ & $192 \mathrm{HV}$ & $223 \mathrm{HV}$ \\
\hline Medida 05 & $210 \mathrm{HV}$ & $183 \mathrm{HV}$ & $212 \mathrm{HV}$ \\
\hline $\begin{array}{c}\text { Desvio } \\
\text { Padrão com } \\
\text { 5 pontos }\end{array}$ & $126 \mathrm{HV}$ & $209 \mathrm{HV}$ & $224 \mathrm{HV}$ \\
\hline
\end{tabular}

Fonte: próprio autor.

O gráfico abaixo foi obtido da média dos 5 medidas de microdureza.

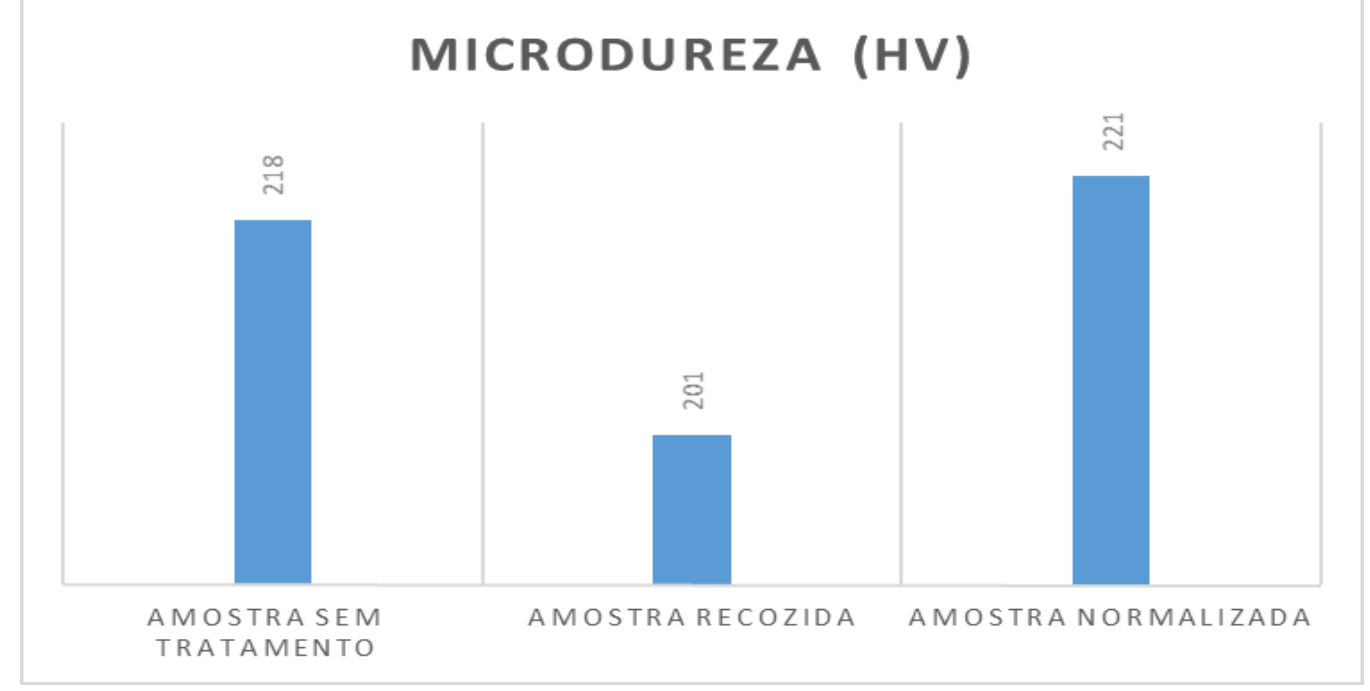

Fonte: próprio autor.

Gráfico 1: Comparativo de microdureza das amostras. 
Os resultados do ensaio de microdureza Vickers na tabela 2 e no gráfico 1 mostra uma dureza maior para amostra normalizada em comparação com as outras duas. Isso ocorre devido à característica da normalização que diminui o tamanho das lamelas, o que aumenta a área superficial para barreiras de discordâncias, impedindo assim a sua movimentação. O inverso acontece para o recozimento pleno, além do fato desse tratamento possibilitar o alívio de tensões residuais da amostra, diminuindo assim a dureza do material.

Vale ressaltar que, apesar dos tratamentos térmicos realizados alterarem as propriedades mecânicas do aço, percebe-se que essa alteração foi pequena, principalmente, entre a amostra recebida e normalizada. Essa pequena alteração é explicada pelo fato que a tendência da austenita ao super resfriamento aumenta com a elevação de sua composição em carbono e elementos de liga. Por isso, a diferença nas propriedades após o recozimento e a normalização depende da composição do aço. Isso dá margem a possíveis questionamentos da viabilidade econômica desses tratamentos em aço baixo e médio carbono.

\section{CONCLUSÃO}

Nesse trabalho, conseguiu-se proceder com todas as etapas de metalografia e tratamentos para verificar a variação de dureza com os tratamentos térmicos de recozimento pleno e normalização. Verificou-se que o aço normalizado apresentou maior dureza explicada com o auxílio das imagens de MEV. Pela análise das imagens de microestrutura e pelo uso do programa Image $\mathrm{J}$ foi possível concluir que 0 aço desconhecido realmente se tratava de um aço $\mathrm{Fe}-\mathrm{C}$ com $0,55 \%$ de $\mathrm{C}$.

Em suma, o presente trabalho conclui-se com êxito, pois os objetivos iniciais foram auferidos, sendo necessários outros ensaios para dar continuidade ao estudo, por exemplo, ensaio de tração.

\section{AGRADECIMENTOS}

Agradecemos à Fundação Cearense de Apoio ao Desenvolvimento Científico e Tecnológico (FUNCAP) pela concessão de bolsa e ao Laboratório de Metalografia, Laboratório de Pesquisa em Corrosão e Laboratório de Caracterização de Materiais do Departamento de Engenharia Metalúrgica e Materiais da UFC pela disponibilidade de materiais e equipamentos. Ao Laboratório de Mecânica da Fadiga e Fratura pela doação de amostra para caracterização.

\section{REFERÊNCIAS}

1 SANT'ANA, P.J.P. As parcerias para a bioprospecção no Brasil. Parcerias Estratégicas, Brasília, DF, n. 15, p .111-127, out. 2002.

2 MEDINA, S.F., LÓPEZ, F.; MORCILLO, M. La investigación siderúrgica en el CENIM. Revista de Metalurgia, v. 39, n. 2, p. 193-204, mayo-jun. 2003.

3 MARINI, Onildo João. Panorama técnico-científico do setor mineral brasileiro. Parcerias Estratégicas, n.11, jun. $2001 . \quad$ Disponível em: <http://www.mct.gov.br/CEE/revista/Parcerias11/05onildomendes.PDF> Acesso em: 30 out. 2003. 
4 LEITE, P.R. Logística reversa: meio ambiente e competitividade. São Paulo: Prentice Hall, 2003.It

5 LEITE, P.R. Logística reversa: um interesse crescente. In: . Logística reversa: meio ambiente e competitividade. São Paulo: Prentice Hall, 2003. cap. 2, p. 15-30.

6 BARBOSA, J.P. Refino de ouro. In: TRINDADE, R.B.E.; BARBOSA FILHO, O. (Ed.). Extração de ouro: princípios, tecnologia e meio ambiente. Rio de Janeiro: CETEM/MCT, 2002. cap. 6, p. 157-177.

7 XAVIER, R. R.; CARVALHO, M. A.; BOCALLINI JUNIOR, M.; SINATORA, A.; SOUZA, R. M. Desenvolvimento e caracterização de desgaste de cilindros para laminadores de tiras a quente. In: SEMINÁRIO DE LAMINAÇÃO, PROCESSOS E PRODUTOS LAMINADOS E REVESTIDOS, 40., 2003, Vitória. São Paulo: ABM, 2003. p. 215-223.

8 LISERRE JUNIOR, G. A aplicação de ligas de magnésio na indústria automotiva. In: SEMINÁRIO DE METAIS NÃO FERROSOS, 10., 2002, São Paulo. Anais... São Paulo: ABM, 2002. 1 CD. 